\title{
Professor V. Raghavan's Evaluations of Ternary Phase Diagrams: An Appreciation
}

John E. Morral

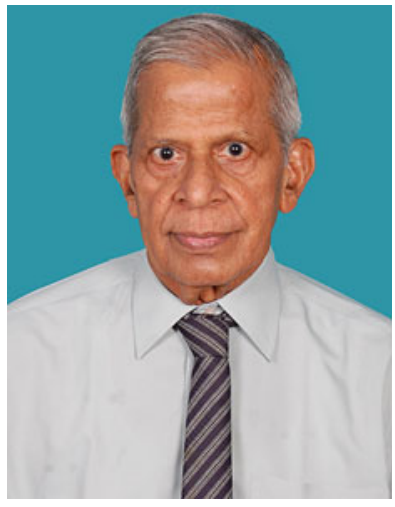

For more than a decade, evaluations of ternary phase diagrams by our Associate Editor, Professor V. Raghavan, have been a regular feature of this journal. As an Emeritus Professor of the Indian Institute of Technolgy Delhi and the author of numerous monographs and technical articles on ternary and quaternary systems, he has been exceptionally qualified for this activity. His attention to the rules of phase diagram construction and his knowledge of previous work in the literature could be seen in each of his carefully drawn isotherms, isopleths, and liquidus projections as well as in his critical comments on previous work.

Although he has agreed to continue in his role as Associate Editor of the Journal of Phase Equilibria and Diffusion, Professor Raghavan has decided that on the occasion of his 80th birthday he will no longer produce the evaluations. It is with much appreciation that all of us associated with JPED acknowledge the quality service he has given to the Journal with his evaluations and to his service to the profession by promoting the use of multicomponent phase diagrams by making them available for applications.

\section{Additional Background}

Dr. Raghavan received his bachelor's degree in metallurgy from Banaras Hindu University. He did his doctoral research at the University of Sheffield, U.K., where his thesis won him the Brunton Medal. He taught metallurgy and materials science courses at the Massachusetts Institute of Technology, U.S.A. from 1969 to 1971.

Dr. Raghavan has authored or coauthored nearly 100 research papers, which include a large number of papers on martensitic transformations in iron alloys. He has published a series of five monographs on ternary phase iron alloys, another on quaternary alloys, and over 600 evaluations in the Journal of Phase Equilibria and Diffusion. He is a Fellow of ASM and an Honorary Member of the Indian Institute of Metals, who have supported his work financially over many years. In addition, he was awarded the 2001 Hume-Rothery Prize from the Institute of Metals London.

John E. Morral, Ohio State University, Columbus, OH, USA. Contact e-mail: jemorral@gmail.com. 